\title{
The increasing role of metacognitive skills in math: a cross-sectional study from a developmental perspective
}

\author{
Manita Van der Stel • Marcel V. J. Veenman • \\ Kim Deelen · Janine Haenen
}

Accepted: 3 November 2009/Published online: 2 December 2009

(C) The Author(s) 2009. This article is published with open access at Springerlink.com

\begin{abstract}
Both intelligence and metacognitive skillfulness have been regarded as important predictors of math performance. The role that metacognitive skills play in math, however, seems to be subjected to change over the early years of secondary education. Metacognitive skills seem to become more general (i.e., less domain-specific) by nature (Veenman and Spaans in Learn Individ Differ 15:159-176, 2005). Moreover, according to the monotonic development hypothesis (Alexander et al. in Dev Rev 15:1-37, 1995), metacognitive skills increase with age, independent of intellectual development. This hypothesis was tested in a study with 29 second-year students (1314 years) and 30 third-year students (14-15 years) in secondary education. A standardized intelligence test was administered to all students. Participants solved math word problems with a difficulty level adapted to their age group. Thinking-aloud protocols were collected and analyzed on the frequency and quality of metacognitive activities. Another series of math word problems served as post-test. Results show that the frequency of metacognitive activity, especially those of planning and evaluation, increased with age. Intelligence was a strong predictor of math performance in 13- to 14-year-olds, but it was less prominent in 14- to 15-year-olds. Although the quality of metacognitive skills appeared to predict math performance in both age groups, its predictive power was stronger in 14- to 15-yearolds, even on top of intelligence. It bears relevance to math
\end{abstract}

M. Van der Stel $(\bowtie) \cdot$ M. V. J. Veenman · K. Deelen ·

J. Haenen

Leiden University, Leiden, The Netherlands

e-mail: mvdstel@planet.nl education, as it shows the increasing relevance of metacognitive skills to math learning with age.

\section{Introduction}

Flavell $(1976,1979)$ considered metacognition as a very powerful predictor of learning performance. Based on a meta-review of studies, Wang, Haertel, and Walberg (1990) concluded that metacognition is the most important predictor of learning performance in general. At the initial stage of mathematical problem solving, metacognitive skills of orientation and planning play an important role in preventing students from a trial-and-error approach and allow students to use prior knowledge in a strategic way by determining what information is given and what is asked for (Desoete \& Veenman, 2006). Metacognitive skills of monitoring and evaluation facilitate students to avoid or repair errors during the math problem-solving process, detect progression being made and compare the answer given against the problem statement (Veenman, Kok, \& Blöte, 2005). In fact, metacognition is omnipresent in mathematical problem solving.

This cross-sectional study focuses on the development of metacognitive skillfulness during math problem solving. The following issues will be investigated: To what extent do metacognitive skills develop between the age of 13 and 15 years? Is there a difference in development between various components of metacognitive skillfulness? How do metacognitive skills relate to intellectual ability (IA) as predictors of math performance and, more importantly, how does this relationship develop? The answers to these questions could help us to understand when and how metacognitive skills develop and its educational consequences for math. 


\subsection{Metacognitive skillfulness}

The distinction between metacognitive knowledge and metacognitive skills has been generally accepted. Metacognitive knowledge refers to the declarative knowledge one has about the interplay between personal characteristics, task characteristics, and available strategies in a learning performance (Flavell, 1979). This knowledge, however, is not always applied when necessary, even when people do have it at their disposal. Alexander, Carr, and Schwanenflugel (1995) found a discrepancy between children's knowledge about monitoring and applying monitoring skills during task performance. Winne (1996) stated that knowledge has no effect on behavior until it is actually needed. So, it is quite possible that children may have knowledge of a certain strategy at their disposal, but still do not spontaneously produce those strategies (Barnett, 2000; Focant, Grégoire \& Desoete, 2006; Pressley, Yokoi, Van Meter, Van Etten, \& Freebern, 1997).

Metacognitive skills, on the other hand, refer to the procedural knowledge that is required for the actual regulation of, and control over, one's learning performance (Brown \& DeLoache, 1978; Veenman, Elshout, \& Meijer, 1997). Metacognitive skills can be inferred from students' overt behavior or utterances, i.e., from concrete metacognitive activities (see Table 1). Some of these activities occur at the onset of task performance (orientation), during task performance (planning, monitoring, evaluation) and at the end of task performance (reflection and elaboration).

Metacognitive skills appear to be highly interdependent, also for math tasks (Veenman \& Spaans, 2005). When orienting thoroughly on a task, a student probably will build a deeper representation of the problem. Consequently, the student will be able to work according to a detailed plan, which enables him/her to monitor and control the learning process. Finally, such a clear trace of problem-solving activities, including repairs of errors made, provides an opportunity for learning through reflection in future occasions.

Over the last few decades, several studies have focused on the use of metacognitive skills, in general, while performing different tasks, for instance, reading comprehension
Table 1 Examples of mathspecific and general metacognitive activities

\begin{tabular}{|c|c|c|}
\hline Subscale & Math specific & General \\
\hline \multicolumn{3}{|c|}{ Orientation } \\
\hline a. & n....... & Activating prior knowledge \\
\hline b. & $\ldots \ldots \ldots$ & Goal setting \\
\hline c. & Estimating the answer & ......... \\
\hline d. & $\begin{array}{l}\text { Making a sketch of the problem to } \\
\text { represent the problem }\end{array}$ & ......... \\
\hline \multicolumn{3}{|l|}{ Planning } \\
\hline a. & ......... & Subgoaling \\
\hline b. & -.w.... & Time management \\
\hline c. & $\begin{array}{l}\text { Designing a step-by-step action } \\
\text { plan, instead of working by trial } \\
\text { and error }\end{array}$ & ......... \\
\hline d. & $\begin{array}{l}\text { Writing down calculations } \\
\text { step-by-step }\end{array}$ & n....... \\
\hline \multicolumn{3}{|l|}{ Evaluation } \\
\hline a. & $\ldots \ldots \ldots$ & Expressing non-understanding \\
\hline b. & $\ldots \ldots \ldots$ & Comment on own activities \\
\hline c. & Monitoring action plan & ......... \\
\hline d. & $\begin{array}{l}\text { Checking an answer by } \\
\text { recalculating }\end{array}$ & ......... \\
\hline \multicolumn{3}{|c|}{ Elaboration } \\
\hline a. & n....... & $\begin{array}{l}\text { Recapitulating and drawing } \\
\text { conclusions }\end{array}$ \\
\hline b. & ......... & $\begin{array}{l}\text { Relating the answer to the } \\
\text { question or problem }\end{array}$ \\
\hline c. & Paraphrasing the problem & ......... \\
\hline d. & $\begin{array}{l}\text { Drawing conclusions while } \\
\text { referring to the problem } \\
\text { statement }\end{array}$ & $\ldots \ldots \ldots$ \\
\hline
\end{tabular}


(Markman, 1977, 1979; Pressley \& Afflerbach, 1995; Veenman \& Beishuizen, 2004) or problem solving (Carr \& Jessup, 1995; Christoph, 2006; Mevarech \& Fridkin, 2006; Schoenfeld, 1992; Veenman \& Spaans, 2005; Veenman, Wilhelm, \& Beishuizen, 2004). Others focused on one or more separate components of metacognitive skills, such as planning (Shore \& Lazar, 1996; Focant et al., 2006) or monitoring skills (Mengelkamp \& Bannert, 2008).

This study, however, focused on all metacognitive skills prior to, during and after task performance in math. Hence, orientation, planning, monitoring as well as reflection skills have been included in this study.

\subsection{Development of metacognitive skills}

The first objective of this study was to investigate the development of metacognitive skillfulness during math performance in particular. Flavell (1992) related the concept of metacognition to Piaget's developmental stage of formal-operational thinking (Inhelder \& Piaget, 1958). At this stage, children are capable of hypothetico-deductive reasoning, which requires metacognitive control. Flavell indicated that Piaget did not expect metacognition to show up before the stage of formal-operational thinking had been reached. More recent studies, however, show that, alongside with the "theory of mind", i.e., understanding of one's own and other people's state of mind (Wellman, 1990), young preschoolers already start developing a metacognitive awareness (Blöte, Van Otterloo, Stevenson, \& Veenman, 2004; Demitriou \& Efklides, 1990; Kuhn, 1999). In later childhood, not only metacognitive knowledge, but also metacognitive skills develop. Although Whitebread et al. (2009) found some planning and monitoring activities in playful situations with youngsters as young as 5 years old, it is generally assumed that the development of metacognitive skills in educational contexts commences around the age of 8-10 years (Berk, 2006; Kuhn, 1999; Siegler, 1998; Veenman, Van Hout-Wolters, \& Afflerbach, 2006).

From a developmental perspective, it is interesting to investigate the development of the aforementioned four components of metacognitive skillfulness in relation to each other. To be able to offer students an appropriate metacognitive instruction in math, it would be useful to understand more about the development of these specific skills, in particular, about the sequence in which they develop over the years. Focant et al. (2006) found positive and significant relations between planning and control activities, on the one hand, and school achievement, on the other. They also found that most children were able to correctly specify the goals of an arithmetical problem at the end of elementary school. On the other hand, they found that most children, although possessing sufficient content knowledge, did not succeed in detecting their errors. Apparently, monitoring and evaluation are more abstract metacognitive skills that arise later in the developmental trajectory (Veenman et al., 2006).

Studying the developmental trajectory of metacognitive skillfulness in math, two different measurement perspectives can be taken: the quantity and the quality of metacognitive skills. Quantity concerns the frequency of applying those skills, whereas quality concerns their level of adequate utilization. Using metacognitive skills more frequently does not automatically mean that the metacognitive skills have a higher level of quality. More is not always better. In a cross-sectional study on the quantity of metacognitive skills, Veenman et al. (2004) found a linear growth in the quantity of metacognitive skills between the age of 9 years and young adults when performing a discovery learning task. In another study (Veenman \& Spaans, 2005), a significant growth in the quality of students' metacognitive skills (12-15 years) was found for both discovery learning task and problem-solving task. In a pilot study, Veenman (2006) found a similar growth in metacognitive quality for math between 12 and 15 years. In line with these results, we expect metacognitive skills in mathematics to increase in frequency as well as in quality over the years.

The second objective of this study was to investigate the relation between metacognitive skills, intellectual ability, and learning performance in math from a developmental perspective. Several researchers (Alexander et al., 1995; Borkowski \& Peck, 1986; Cheng, 1993; Hannah \& Shore, 1995; Schneider \& Pressley, 1997; Span \& OvertoomCorsmit, 1986; Veenman, 2006; Veenman \& Spaans, 2005; Veenman et al., 2004; Zimmerman \& Martinez-Pons, 1990) investigated metacognitive ability in relation to intellectual ability. In the next section, this relation will be discussed.

\subsection{Relation between metacognitive ability, intellectual ability, and learning performance in math from a developmental perspective}

Veenman (Veenman et al., 1997, 2004; Veenman \& Spaans, 2005) described three mutually exclusive models concerning the relation between intellectual ability and metacognitive skillfulness as predictors of learning performance. The intelligence model regards metacognitive skillfulness as an integral part of intellectual ability. In this model, metacognitive skillfulness does not contribute to learning performance independent of intellectual ability. According to this model, metacognitive skills cannot have a predictive value for learning performance independent of intellectual ability. Sternberg (1990), for instance, advocates such an inclusive position of "metacomponents" in 
his triarchic theory of intelligence. The second, contrasting model is the independency model, in which intellectual ability and metacognitive skillfulness are regarded as entirely independent predictors of learning performance. Finally, in the mixed model, intellectual ability and metacognitive skillfulness are correlated to a certain extent, but metacognition has its own, unique contribution to the prediction of learning performance, on top of intellectual ability.

Over the last decades, support has been found for each of these models by various researchers (for an overview, see Veenman \& Spaans, 2005; Veenman et al., 2004). However, it is difficult to compare many studies, due to dissimilarities in the assessment method of metacognitive skillfulness (thinking-aloud observations vs. questionnaires), in participants (age, educational background), and in tasks and domains. Moreover, the focus of some studies is restricted to the relation between intellectual ability and metacognitive skillfulness, thereby excluding the relation of both predictors with learning performance (Alexander et al., 1995; Berger \& Reid, 1989; Span \& OvertoomCorsmit, 1986; Shore \& Dover, 1987; Stankov, 2000). The evidence found so far seems to be highly in favor of the mixed model. Many studies, however, deal with the metacognitive skillfulness of older secondary school or university students. From the perspective of the development of metacognitive skills, it remains to be ascertained more thoroughly whether the mixed model can be generalized to younger students at the crucial point of developing initial metacognitive skills. Therefore, in the present study, the participants are young secondary school students (aged 13-15 years) who are engaged in performing math school tasks.

From a developmental perspective, a relevant research question is whether the development of metacognitive skills is intelligence related or relatively intelligence independent according to the mixed model. Alexander et al. (1995) formulated three developmental hypotheses with regard to the relation between intellectual ability and the development of metacognition, though excluding the relation of both predictors with learning performance. The ceiling hypothesis assumes that the effects of intelligence on the development of metacognition diminish over time. The acceleration hypothesis, on the other hand, predicts that the impact of intelligence on the development of metacognition increases with age. The monotonic development hypothesis, finally, assumes that both intelligence and metacognition show a monotonic growth over age. When taking the relations of both predictors with learning performance into account, the last hypothesis would be in line with the mixed model, as both intellectual ability and metacognition would have a substantial independent contribution to learning outcomes. Support for the intelligence model, on the other hand, would support the acceleration hypothesis, as the influence of intellectual ability on metacognition would increase with age. Finally, the ceiling hypothesis predicts that the intelligence model will fit less with age. The independency model fits none of Alexander's hypotheses, since it predicts that there is no relation between intelligence and metacognition at all. In their literature overview, Alexander et al. (1995) found support for the monotonic development of metacognitive knowledge. Gifted children showed a general superiority in their declarative metacognitive knowledge. Giftedness effects were persistent throughout childhood, with gifted early elementary school children showing a similar superiority in this knowledge as did junior high school students. With regard to metacognitive skills, however, the results were inconclusive. In a cross-sectional study, Veenman (2006) and Veenman and Spaans (2005) obtained evidence in favor of a monotonic development of metacognitive skills. They obtained support for a monotonic maturation effect of both intellectual ability and metacognitive skillfulness in students of 12 and 15 years performing various problemsolving tasks. We hypothesize that metacognitive skillfulness develops alongside, but is not fully dependent on intellectual ability. Therefore, we expect to find a parallel development of metacognitive skillfulness and intellectual ability as predictors of math learning performance in line with the mixed hypothesis and the monotonic development model.

\subsection{Research questions and hypotheses}

The first research question is whether metacognitive skills in math do develop over age. We expect these metacognitive skills to increase in frequency as well as in quality over the years.

The second research question relates to the development of the relation among metacognitive skills, intellectual ability, and math performance. We expect to find a parallel development of metacognitive skills and intellectual ability as predictors of math performance in line with the monotonic development hypothesis and the mixed model.

\section{Methods}

\subsection{Participants}

Twenty-nine second-year students (13-14 years; 11 boys and 18 girls) and 30 third-year students (14-15 years; 12 boys and 18 girls) in secondary education participated in this study. They were recruited from three different tracks (pre-university education, higher general education, and pre-vocational education) of two suburban schools in the 
Netherlands. Both schools are well known because of their large diversity of children, thus representing a broad educational level of the students, a broad range of social economic status of parents, and various ethnic backgrounds. Participants were distributed equally over the three tracks. Students with learning or conduct disorders (e.g., dyslexia or ADHD) were excluded from the study. Parental consent was requested and given for all participants.

\subsection{Metacognitive skillfulness}

Thinking-aloud protocols were analyzed on spontaneous use of metacognitive skills according to the procedure of Veenman (Prins, Veenman, \& Elshout, 2006; Van der Stel \& Veenman, 2008; Veenman \& Spaans, 2005; Veenman et al., 2004). Metacognitive skillfulness was divided into four subscales: orientation $(\mathrm{O})$, planning and systematical orderliness (P), evaluation (Ev), and elaboration (El). In Table 1, examples of such activities are given for each subscale of metacognitive skillfulness. These activities are partly characteristic of metacognitive skillfulness, in general (Brown, 1978; Sternberg, 1990; Veenman et al., 1997), and partly domain-specific for math (de Corte \& Verschaffel, 1980; Gagné, Yekovich, \& Yekovich, 1993; Schoenfeld, 1983). For example, goal setting is an activity independent of tasks and domains. Writing down calculations step-by-step, on the other hand, is related to a math task, whereas in a text-studying task, summarizing the text after each paragraph is considered as a planning activity. Note that some of the behavior in Table 1 may be considered as cognitive, but the purposeful application of such cognitive behavior at the appropriate moment results from metacognitive skillfulness. It reflects the intention to get control over and regulate the cognitive task. For example, the recalculation of the answer itself is cognitive by nature, but it is the decision to check one's outcomes at a particular point in time that constitutes the metacognitive nature of the activity.

The scoring method consisted of two steps for each protocol. First, an utterance was coded in the margin if belonging to one of the four subscales $(\mathrm{O}, \mathrm{P}, \mathrm{Ev}$, or $\mathrm{El})$. This resulted in a quantitative score obtained by counting the frequency of metacognitive activities on each subscale (e.g., if a student checked the calculations five times, the quantitative score for evaluation was five). Secondly, for each subscale, the criteria that should be met to obtain a certain rate for the quality of metacognitive skillfulness were described. So, each subscale received a qualitative score according to the formulated criteria on a five-point scale (ranging from 0 to 4 ). For example, a participant received a higher score for a "deeper" orientation (e.g., making a sketch of the problem to represent the problem) than for a superficial one (e.g., only partly reading the problem statement). It is important to emphasize that the judges intentionally avoided confounding metacognition scores with the correctness or incorrectness of the content matter. A properly argued, yet incorrect, conclusion would yield a similar score for elaboration as a correct conclusion would.

Two judges independently rated six protocols of both years. This resulted in an interrater reliability of 0.95 (second year) and 0.98 (third year) for the qualitative scores, and 0.94 (second year) and 0.86 (third year) for the quantitative scores. These correlations were computed on the summed scores over the four subscales of metacognition.

\subsection{Intellectual ability}

In two group sessions, the intellectual ability of 59 students (29 second and 30 third year) was assessed by a series of ability tests. Three subtests of the Groninger Intelligence test for Secondary Education (GIVO, standardized Dutch intelligence test; Van Dijk \& Tellegen, 1994) were selected: number series, verbal analogies, and unfolding figures. With these subtests, three primary factors of intelligence (Carroll, 1993) were assessed: inductive and deductive reasoning abilities, both verbal and numerical, and visuospatial ability. The GIVO, however, lacks a test for assessing memory abilities, another primary factor in Carroll's (1993) model. Therefore, a fourth test (Names \& Professions, requiring the memorization of word pairs; see Veenman \& Beishuizen, 2004) was administered. A total score for intellectual ability was calculated by transforming the individual test score into $z$ scores and then calculating an unweighted mean score for each participant.

\subsection{Tasks}

For each year, participants were administered math tasks with task demands suitable for their age. The tasks were piloted with appropriate age groups beforehand and teachers were consulted about the suitability of the tasks.

In an individual session of $50 \mathrm{~min}$, the participants learned to solve mathematical word problems in $20 \mathrm{~min}$. Six problems were presented in the second year and five in the third. Several categories of problems were presented. In the second year, the categories of the problems were content, surface area of a triangle, fraction, percentage, and algebra. For instance, an algebraic problem was: "In a village are two camping sites. At the first one you pay for the rent of a caravan 20 euros cleaning costs plus 5 euros a day. At the second one you pay 40 euros cleaning costs and two euros a day. Which site would you choose if you wanted to stay eight days? Show your calculations". In the 
third year, the categories of the problems were calculation of probability, quadratic equation, Pythagoras' theorem, statistics, and formula with a square root. For instance, a problem was: "In the center of a city the air pollution on one day is given by the formula $\mathrm{V}=-0.2 \mathrm{t}^{2}+3.1 \mathrm{t}+1.7$, where $\mathrm{V}=$ air pollution in grams per $\mathrm{m}^{3}$ and $\mathrm{t}=$ point in time in hours. A) Calculate V for 8.15 a.m. B) Calculate the percentage of difference in pollution between 7 and 11 a.m." Both tasks for second- and third-year students were composed of adaptations of math problems from one of the most frequently used Dutch schoolbooks for math ("Getal en Ruimte"; Vuijk et al., 2003).

Together with the assignments, participants received a sheet containing the answers and a brief stepwise explanation on how to solve the problems. Participants were free to consult this sheet whenever and as much as they liked. The first 20 min of the session was considered as a learning-by-doing phase. Next, the participants handed in all materials and received another series of parallel problems, which had to be solved without any help in the remaining $30 \mathrm{~min}$. This second part was considered as a post-test assessment of learning performance (see Sect. 2.5). All problems had to be solved while thinking aloud.

\subsection{Learning performance}

After the learning-by-doing phase, the learning performance was assessed by the post-tests, as was explained to the participants in advance. In both years, the post-test items were parallel to the items in the learning phase, i.e., the surface structure of the post-test items differed from the one in the learning task items, but the deep structure was the same.

In the second year, the post-test consisted of six math word problems. For each problem, an equal amount of ten points could be earned. According to a rating system, points were given for the steps that had to be made to come to a correct solution. So, the maximum obtainable score was 60 points. A total score was calculated and used as a measure of learning performance. Cronbach's $\alpha$ was 0.66 . In the third year, the post-test consisted of five math word problems. The items were rated in the same way as in the second year. The maximum obtainable score was 50 points. Cronbach's $\alpha$ was 0.67 .

\subsection{Procedure}

The intellectual ability test was administered during a group session of $100 \mathrm{~min}$. The math tasks were presented in an individual thinking-aloud session of $50 \mathrm{~min}$. Participants could make use of a pen, pencil, text highlighter, ruler, calculator, and blank sheets of paper for making notes and/or calculations.
All participants were instructed to think aloud during the individual session. The experimenter was not allowed to help the students in any way. To encourage the student to keep on thinking aloud, the experimenter used standard prompts (e.g., "please, keep on thinking aloud") whenever the student fell silent. All the utterances of the participants were audio-taped, transcribed and analyzed in relation to metacognitive skillfulness.

\section{Results}

3.1 Development of metacognitive and intellectual abilities

To establish a continuous growth in both metacognitive and intellectual abilities, the results of both age groups (second- and third-year students) were compared. First, MANOVAs were performed on the metacognition and intellectual ability scores with age as between-groups factor. Next, univariate tests were performed. Results of the MANOVA on the raw scores of intellectual ability revealed a significant age effect $[F(4,54)=3.93, p<0.01$, $\left.\eta^{2}=0.23\right]$. Third-year students had a higher intellectual ability score than second-year students. Results of the MANOVAs on both the quantitative $[F(4,54)=13.84$, $\left.p<0.001, \eta^{2}=0.51\right]$ and the qualitative $[F(4,54)=4.90$, $\left.p<0.005, \eta^{2}=0.27\right]$ scores of metacognitive skills revealed a significant age effect as well. So, third-year students had higher metacognition scores than second-year students. Thus, both intellectual and metacognitive abilities show an increase between the second and third year in secondary education.

Results of the subsequent univariate tests on the subscales of intellectual ability and metacognition scores show a significant growth over the years (see Table 2). With the exception of the quantity of orientation activities, results of the univariate tests show an increase in all the components of intellectual and metacognitive abilities.

\subsection{Development of the relation between intellectual and metacognitive abilities as predictors of math performance: testing the mixed model and the monotonic development hypothesis}

To be able to answer the question whether developmental processes affect the relation among intellectual ability, metacognitive skillfulness, and math performance, correlations among these three variables were calculated for both groups separately (see Table 3). In the correlational analyses, the subtest scores for intellectual ability were transformed into one total score. This IA score was obtained by transforming the raw scores on all subtests into 
Table 2 Comparison of the results of second and third year

Because the total scores for intellectual ability were transformed into $z$ scores, the means and standard deviations for intellectual ability were the scores for the subtests of the intelligence and memory tests

Metaskills metacognitive skills, OrQL quality of orientation, $P l Q L$ quality of planning, $E v Q L$ quality of evaluation, ElQL quality of elaboration, $\mathrm{OrQN}$ quantity of orientation, Intel intellectual ability, Numbers number series, Verbal Ana verbal analogies, Unfol Fig unfolding figures

\begin{tabular}{llllll}
\hline & $M(\mathrm{SD})$ & & $F$ & & $\eta^{2}$ \\
\cline { 2 - 3 } & $\begin{array}{l}\text { Second year } \\
(N=29)\end{array}$ & $\begin{array}{l}\text { Third year } \\
(N=30)\end{array}$ & & \\
\hline Metaskills & & & & \\
OrQL & $1.69(0.76)$ & $1.93(0.94)$ & 1.19 & n.s. & 0.02 \\
PlQL & $1.83(0.80)$ & $2.73(1.11)$ & 12.77 & $<0.005$ & 0.18 \\
EvQL & $1.14(0.88)$ & $1.93(1.14)$ & 8.97 & $<0.005$ & 0.14 \\
ElQL & $0.83(0.85)$ & $0.90(1.19)$ & 0.07 & n.s. & 0.00 \\
OrQN & $7.90(1.54)$ & $5.13(3.20)$ & 17.62 & $<0.001$ & 0.24 \\
PlQN & $5.31(2.42)$ & $8.83(3.98)$ & 16.76 & $<0.001$ & 0.23 \\
EvQN & $2.62(2.47)$ & $7.07(4.30)$ & 23.53 & $<0.001$ & 0.29 \\
ElQN & $0.83(0.90)$ & $1.80(2.19)$ & 4.94 & $<0.05$ & 0.08 \\
Intel & & & & & \\
Numbers & $17.28(4.42)$ & $21.07(3.71)$ & 12.77 & $<0.005$ & 0.18 \\
Verbal Ana & $13.79(3.92)$ & $16.07(3.45)$ & 6.56 & $<0.05$ & 0.10 \\
Unfol Fig & $13.79(3.92)$ & $16.37(3.94)$ & 6.31 & $<0.05$ & 0.10 \\
Memory & $17.24(5.52)$ & $19.17(6.12)$ & 2.45 & n.s. & 0.04 \\
\hline
\end{tabular}

Table 3 Correlations among intellectual ability, metacognition, and math performance for both age groups separately

\begin{tabular}{|c|c|c|c|c|c|c|}
\hline & \multicolumn{3}{|l|}{ Second year } & \multicolumn{3}{|l|}{ Third year } \\
\hline & Intellectual ability & MetaQL & MetaQN & Intellectual ability & MetaQL & MetaQN \\
\hline Math performance & $0.79 * *$ & $0.53 * *$ & 0.29 & $0.46^{*}$ & $0.78^{* *}$ & $0.40 *$ \\
\hline MetaQL & $0.46 * *$ & & & $0.37 *$ & & \\
\hline MetaQN & $0.39 *$ & $0.73 * *$ & & 0.16 & $0.74 * *$ & \\
\hline
\end{tabular}

MetaQL the total score on the quality of metacognition, MetaQN the total score on the quantity of metacognition

$* p<0.05, * * p<0.01$

$z$ scores and then calculating the mean $z$ score for secondand third-year students separately (see Sect. 2.3). The total score of the quantity of metacognitive skillfulness was obtained by adding the quantitative subscale scores of metacognition. The same procedure was repeated for the quality of metacognitive skillfulness.

Results show that nearly all correlations between intellectual ability, quantity and quality of metacognitive skillfulness, and math performance were significant. The only exceptions were the correlation between the quantity of metacognitive skillfulness and math performance (second year), and the correlation between intellectual ability and the quantity of metacognitive skillfulness (third year).

To test the mixed model, the semi-partial correlations for both groups (Nunnally, 1967) were calculated by partialling metacognitive skillfulness from the correlations between intellectual ability and math performance (i.e., semi-partIntel) and partialling intellectual ability from the correlation between metacognitive skillfulness and math performance (i.e., semi-partMeta). These semi-partial correlations (see Table 4) are needed to calculate the unique contribution of metacognitive and intellectual abilities to math performance.

Using regression-analytic techniques (Pedhazur, 1982; Van der Stel \& Veenman, 2008; Veenman \& Spaans, 2005; Veenman et al., 2004), the unique and shared variances in the math performance were distributed to metacognitive skillfulness and intellectual ability (see Table 5). The math data of the second-year students could be taken as an example. The squared multiple correlation of intellectual ability and metacognitive skillfulness for predicting the math performance was calculated from the correlations presented in Tables 3 and $4\left(R^{2}=\right.$ the squared correlation between intellectual ability and math performance + the squared semi-partial correlation between metacognitive skillfulness and math performance with intellectual ability partialled out $=0.79^{2}+0.21^{2}=0.67$ ). The unique contribution of intellectual ability to math performance was determined by calculating the squared semi-partial correlation between intellectual ability and math performance with metacognition partialled out from intellectual ability $\left(r^{2}=0.336\right)$. Consequently, it was estimated that 
Table 4 Semi-partial correlations

\begin{tabular}{|c|c|c|c|c|c|c|c|c|}
\hline & \multicolumn{2}{|c|}{ Semi-partIntel second year } & \multicolumn{2}{|c|}{ Semi-partMeta second year } & \multicolumn{2}{|c|}{ Semi-partIntel third year } & \multicolumn{2}{|c|}{ Semi-partMeta third year } \\
\hline & QL & QN & QL & QN & QL & QN & QL & QN \\
\hline Math performance, second year & $0.58 * *$ & $0.70 * *$ & 0.21 & 0.00 & & & & \\
\hline Math performance, third year & & & & & 0.19 & $0.41 * *$ & $0.65 * *$ & $0.33 *$ \\
\hline
\end{tabular}

$Q L$ qualitative metascores, $Q N$ quantitative metascores

$* p<0.05, * * p<0.01$

Table 5 Percentage of variance accounted for in math performance

\begin{tabular}{|c|c|c|c|c|c|c|c|c|}
\hline & \multicolumn{2}{|c|}{ Intel unique } & \multicolumn{2}{|c|}{ Meta unique } & \multicolumn{2}{|c|}{ Shared } & \multicolumn{2}{|l|}{ Total } \\
\hline & QL & QN & QL & QN & QL & QN & QL & QN \\
\hline Math performance, second year & 33.6 & 49.1 & 4.3 & 0 & 23.9 & 8.4 & 61.8 & 57.8 \\
\hline Math performance, third year & 3.5 & 16.5 & 42.8 & 10.6 & 17.9 & 4.9 & 62.4 & 32.0 \\
\hline
\end{tabular}

Intel unique the unique contribution of intellectual ability to math performance, Meta unique the unique contribution of metacognitive skillfulness to math performance, Shared the shared contribution of intellectual ability and metacognitive skillfulness to math performance, Total the total contribution of intellectual ability and metacognitive skillfulness to math performance, $Q L$ qualitative metacognition scores, $Q N$ quantitative metacognition scores

intellectual ability uniquely accounted for $33.6 \%$ of the variance in math performance, metacognitive skillfulness accounted for $4.3 \%$ of the variance, while both predictors had another $23.9 \%$ of variance in common. This procedure was applied for both age groups (see Table 5).

In both age groups, intellectual ability and the quality of metacognitive skillfulness have their own, unique contribution to the prediction of math performance. In the youngest group, however, there is no unique contribution of the quantity of metacognitive skillfulness to the prediction of math performance.

Comparison of the unique contribution of the quality of metacognitive skillfulness in relation to the contribution of intellectual ability over the years shows that the roles have been turned around. In the youngest group, intellectual ability is the most important predictor of math performance, whereas in the oldest group the contribution of the quality of metacognition outweighs the unique contribution of intellectual ability.

\section{Discussion}

This study investigated the development of both the quantity and the quality of metacognitive skillfulness in math. According to the first hypothesis, we expected a growth in metacognitive skills in math, both in frequency and in quality over the years. Results show an overall growth of quantitative and qualitative metacognitive skillfulness, indeed. Looking closer into the various components of metacognitive skillfulness (orientation, planning, evaluation, and elaboration), results show a significant growth of both the quantity and the quality of planning and evaluation activities. It seemed that not only the quantity of these activities increased significantly between 13 and 15 years, but that also the quality developed in a positive way. The quantity of orientation activities, on the other hand, decreased significantly; this decrease was not reflected in the quality of orientation activities. Possibly, students become more selective in their orientation activities over the years, resulting in fewer, but perhaps better, orientation activities. Also, Mevarech and Amrany (2008) report about students who did not report attempting to comprehend a problem prior to solving it. Finally, the elaboration activities show a significant growth in frequency, but not in quality. Although students increased the number of their elaboration activities between 13 and 15 years, they seemed to experience a problem in abstracting knowledge as a result of these activities. In conclusion, the first hypothesis that the metacognitive skills in math would increase in frequency as well as in quality over the years is generally corroborated. However, results also show that the various components of metacognitive skillfulness differ in their developmental trajectory. "The ages on which strategies are acquired seem to depend largely on the strategy itself" (Focant et al., 2006, p. 61).

It seems that the metacognitive activities that are required during task performance (planning and evaluation) develop in an earlier phase than activities that play a role prior to (orientation) and after (elaboration) task performance. It might be that students experience the activities during task performance to be more concrete and, therefore, easier. Maybe teachers pay more attention to overt 
activities during task performance than to less obvious activities prior to or after task performance.

From an instructional perspective, it would be interesting to learn more about the development of specific components of metacognitive skillfulness and, in particular, the sequence and the pace in which they develop over a longer period of time (Veenman et al. 2006). This would require longitudinal research over an extended period of time.

The second hypothesis concerned the relation between metacognitive skillfulness and intellectual ability as predictors of math performance over the years. The results for both age groups were in line with the mixed model as far as it concerned the qualitative scores for metacognition. As expected, metacognitive skillfulness and intellectual ability were moderately correlated. Moreover, metacognitive skillfulness had its own, unique contribution to math performance in both age groups, on top of intellectual ability. These results are similar to those for older age groups performing different tasks (Veenman \& Beishuizen, 2004; Veenman \& Verheij, 2003; Veenman et al., 2004). Therefore, the mixed model can be generalized to younger students with less developed metacognitive skills performing everyday math school tasks. For the quantity of metacognitive skills, the mixed model could not be corroborated for the youngest group, as no unique contribution of the quantity of metacognition to math performance was obtained, contrary to the older group of students.

On comparing both age groups, an interesting shift in the contribution to math performance occurs. The roles of metacognitive skills and intellectual ability as predictors of math performance have been turned around between 13 and 15 years. In the youngest group, intellectual ability is the most important predictor of math performance, whereas in the oldest group, the contribution of the quality of metacognition outweighs the unique contribution of intellectual ability. The correlation between both predictors of math performance, however, remains practically the same for both age groups. Evidently, it is the growth of metacognitive skills that demands a more prominent role in the math performance of older students.

A parallel development of metacognitive skillfulness and intellectual ability as predictors of math performance was found. This parallel growth is in line with the monotonic development hypothesis. Earlier, Alexander et al. (1995) found a different developmental pattern in the metacognition of gifted and non-gifted children. However, developmental patterns were not consistently found over the different components of metacognition. They obtained evidence in favor of a monotonic development of metacognitive knowledge, but their results were inconclusive on metacognitive skills. The results of our study point in the direction of a monotonic development in metacognitive skills as well: a continuous growth of metacognitive skills with age, alongside intellectual growth (Veenman et al., 2004), corroborating the second hypothesis.

This study focused on students with a normal cognitive development, without learning disabilities or conduct disorders. Participants did not receive any explicit training on metacognition prior to the experiments. Therefore, the growth in metacognitive skillfulness can be considered (partly) as a spontaneous development due to maturation. Testing the metacognitive skillfulness of third graders with mathematical learning disabilities, Desoete (2006), however, found evidence against the maturational development. She found that these children had significantly less accurate evaluation skills on number system knowledge and procedural calculation than younger children with comparable mathematical performance scores. Based on these findings, Desoete (2006) stated that we could not expect metacognition to develop spontaneously as children grow older or as they have more experience with math. Differences in findings can be caused by differences in participants (age, mathematical disabilities) and or by differences in assessing metacognition (thinking aloud during task performance vs. interviews prior to and after task performance).

Despite finding significant results, there might be some limitations of the study. The small number of participants in each group may be considered as a limitation of the generalizability of the results. The same applies to the fact that all participants came from only two schools. Although both schools were highly representative of secondary schools in the Netherlands, yet some confirmation of results from a broader population of schools is needed. Furthermore, it would be interesting for future research to replicate this study with more participants in a longitudinal study over a longer period of time. Special attention should be paid to the developmental trajectory of specific components of metacognitive skillfulness, especially their relation with math performance. At present, studies with multi-method designs are scarcely available in the literature on metacognition. Therefore, it would be worthwhile to have more studies with a multi-method design to compare off-line and online methods of assessment (Van HoutWolters, 2000; Veenman, 2005).

Although metacognitive skills in math seem to develop (partly) as a result of maturation, there are substantial individual differences in the level of metacognitive skillfulness during the developmental trajectory. An important issue in the educational context is, therefore, how the development of metacognitive skills in math can be enhanced.

In the past, various instructional methods to enhance metacognitive skillfulness in math have been developed and used with success. Mevarech and Kamarski (1997) developed a training program called IMPROVE. With this 
program, students are taught to use a series of metacognitive questions during math tasks. Veenman (1998) formulated the WWW\&H rule for training metacognition, referring to instructions about what metacognitive activities should be executed, When, Why, and How. Van Luit and Naglieri (1999) developed a program (MASTER) for teaching math to children in special education. Results with these training methods show that children, varying substantially in intellectual and metacognitive abilities, can benefit from training their metacognitive competencies in math. Training metacognitive skillfulness in math could be very useful as a supplement to spontaneous development, especially if the right component is trained at the right moment in the developmental trajectory.

Open Access This article is distributed under the terms of the Creative Commons Attribution Noncommercial License which permits any noncommercial use, distribution, and reproduction in any medium, provided the original author(s) and source are credited.

\section{References}

Alexander, J., Carr, M., \& Schwanenflugel, M. (1995). Development of metacognition in gifted children: Directions for future research. Developmental Review, 15, 1-37.

Barnett, J. E. (2000). Self-regulated reading and test preparation among college students. Journal of College Reading and Learning, 31, 42-53.

Berger, R., \& Reid, S. (1989). Differences that make a difference: Comparisons of metacomponential functioning and knowledge base among groups of high and low IQ learning disabled, mildly mentally retarded, and normal achieving subjects. Journal of Learning Disabilities, 22, 422-429.

Berk, L. (2006). Child development (7th ed.). Boston: Allyn and Bacon.

Blöte, A. W., Otterloo, S. G., Van Stevenson, C. E., \& Veenman, M. V. J. (2004). Discovery and maintenance of the many-to-one counting strategy in 4-year olds: A microgenetic study. British Journal of Developmental Psychology, 22, 83-102.

Borkowski, J. G., \& Peck, V. A. (1986). Causes and consequences of metamemory in gifted children. In R. J. Sternberg \& J. E. Davidson (Eds.), Knowing, learning, and instruction. Essays in honor of Robert Glaser (pp. 393-451). Hillsdale, NJ: Erlbaum.

Brown, A. L. (1978). Knowing when, where, and how to remember: A problem of metacognition. In R. Glaser (Ed.), Advances in instructional psychology (Vol. 1, pp. 77-165). Hillsdale, NJ: Erlbaum.

Brown, A. L., \& DeLoache, J. S. (1978). Skills, plans, and selfregulation. In R. S. Siegel (Ed.), Children's thinking: What develops? Hillsdale, NJ: Erlbaum.

Carr, M., \& Jessup, D. L. (1995). Cognitive and metacognitive predictors of arithmetics strategy use. Learning and Individual Differences, 7, 235-247.

Carroll, J. B. (1993). Human cognitive abilities. A survey of factoranalytic studies. Cambridge: Cambridge University Press.

Cheng, P. (1993). Metacognition and giftedness: The state of the relationship. Gifted Child Quarterly, 37, 105-112.

Christoph, N. L. H. (2006). The role of metacognitive skills in learning to solve problems. Wageningen: Prinsen \& Looijen.

De Corte, E., \& Verschaffel, L. (1980). Een exploratief onderwijsexperiment met aanvankelijke rekenopgaven bij 6-à 8-jarige kinderen [An exploratory experiment with simple math problems for 6-8-year children]. Pedagogische Studiën, 57, 433-448.

Demitriou, A., \& Efklides, A. (1990). The objective and subjective structure of problem-solving abilities: Metacognitive awareness from early adolescence to middle age. In H. Mandl, E. de Corte, S. N. Bennett, \& H. F. Friedrich (Eds.), Learning and instruction in an international context, Vol 2.1: Social and cognitive aspects of learning and instruction (pp. 161-179). Oxford: Pergamon Press.

Desoete, A. (2006). Are mathematical learning disabilities a special kind of metacognitive disabilities? In A. Desoete \& M. V. J. Veenman (Eds.), Metacognition in mathematics education (pp. 135-156). New York: Nova Science Publishers.

Desoete, A., \& Veenman, M. V. J. (2006). Metacognition in mathematics: Critical issues on nature, theory, assessment and treatment. In Metacognition in mathematics education (pp. 110). New York: Nova Science Publishers.

Flavell, J. H. (1976). Metacognitive aspects of problem-solving. In L. B. Resnick (Ed.), The nature of intelligence (pp. 231-235). Hillsdale, NJ: Erlbaum.

Flavell, J. H. (1979). Metacognition and cognitive monitoring: A new area of cognitive-developmental inquiry. American Psychologist, $34,906-911$.

Flavell, J. H. (1992). Perspectives on perspective taking. In H. Beilin \& P. Pufall (Eds.), Piaget's theory: Prospects and possibilities (pp. 107-141). Hillsdale, NJ: Erlbaum.

Focant, J., Grégoire, J., \& Desoete, A. (2006). Goal-setting, planning and control strategies and arithmetical problem-solving at grade 5. In A. Desoete \& M. V. J. Veenman (Eds.), Metacognition in mathematics education (pp. 51-71). New York: Nova Science Publishers.

Gagné, E. D., Yekovich, C., \& Yekovich, F. R. (1993). The cognitive psychology of school learning. New York: Harper Collins.

Hannah, C. L., \& Shore, B. M. (1995). Metacognition and high intellectual ability: Insights from the study of learning-disabled gifted students. Gifted Child Quarterly, 39, 95-109.

Inhelder, B., \& Piaget, J. (1958). The growth of logical thinking from childhood to adolescence. London: Routledge and Kegan.

Kuhn, D. (1999). Metacognitive development. In L. Balter \& C. S. Tamis-Lemonda (Eds.), Child psychology. A handbook of contemporary issues (pp. 259-286). Philadelphia: Psychology Press.

Markman, E. (1977). Realizing that you don't understand: A preliminary investigation. Child Development, 48, 986-992.

Markman, E. (1979). Realizing that you don't understand: Elementary school children's awareness of inconsistencies. Child Development, 50, 643-655.

Mengelkamp, C., \& Bannert, M. (2008). Accuracy of monitoring: Stability in the learning process and predictive validity on learning outcome. Paper presented at the Earli-SIGMetacognition 2008, Ioannina, Greece.

Mevarech, Z., \& Amrany, C. (2008). Immediate and delayed effects of meta-cognitive instruction on regulation of cognition and mathematics achievement. Metacognition and Learning, 3, 147157.

Mevarech, Z., \& Fridkin, S. (2006). The effects of IMPROVE on mathematical knowledge, mathematical reasoning and metacognition. Metacognition and Learning, 1, 85-97.

Mevarech, Z., \& Kamarski, B. (1997). IMPROVE: A multidimensional method for teaching mathematics in heterogeneous classrooms. American Educational Research Journal, 34, 365-394.

Nunnally, J. C. (1967). Psychometric theory. New York: McGrawHill.

Pedhazur, E. J. (1982). Multiple regression in behavioral research (2nd ed.). Mahwah, NJ: Erlbaum.

Pressley, M., \& Afflerbach, P. (1995). Verbal protocols of reading: The nature of constructively responsive reading. Hillsdale, NJ: Lawrence Erlbaum Associates. 
Pressley, M., Yokoi, L., Van Meter, P., Van Etten, S., \& Freebern, G. (1997). Some of the reasons why preparing for an exam is so hard: What can be done to make it easier? Educational Psychology Review, 9, 1-38.

Prins, F. J., Veenman, M. V. J., \& Elshout, J. J. (2006). The impact of intellectual ability and metacognition on learning: New support for the threshold of problematicity theory. Learning and Instruction, 4, 374-387.

Schneider, W., \& Pressley, M. (1997). Memory development between two and twenty (2nd ed.). Mahwah, NJ: Lawrence Erlbaum Associates.

Schoenfeld, A. H. (1983). Beyond the purely cognitive. Cognitive Science, 7, 329-363.

Schoenfeld, A. H. (1992). Learning to think mathematically: Problem-solving, metacognition, and sense-making in mathematics. In D. Grouws (Ed.), Handbook for research on mathematics and learning (pp. 334-370). New York: MacMillan.

Shore, B. M., \& Dover, A. C. (1987). Metacognition, intelligence and giftedness. Gifted Child Quarterly, 31, 37-39.

Shore, B. M., \& Lazar, L. (1996). IQ-related differences in time allocation during problem-solving. Psychological Reports, 78, 848-849.

Siegler, R. J. (1998). Children's thinking. Upper Saddle River: Prentice-Hall.

Span, P., \& Overtoom-Corsmit, R. (1986). Information processing by intellectually gifted pupils solving mathematical problems. Educational Problems in Mathematics, 17, 273-295.

Stankov, L. (2000). Complexity, metacognition, and fluid intelligence. Intelligence, 28, 121-143.

Sternberg, R. J. (1990). Metaphors of the mind: Conceptions of the nature of intelligence. Cambridge: Cambridge University Press.

Van der Stel, M., \& Veenman, M. V. J. (2008). Relation between intellectual ability and metacognitive skillfulness as predictors of learning performance of young students performing tasks in different domains. Learning and Individual Differences, 18, 128-134.

Van Dijk, H., \& Tellegen, P. J. (1994). GIVO. Groninger Intelligentietest Voortgezet Onderwijs. Lisse: Swets \& Zeitlinger.

Van Hout-Wolters, B. (2000). Assessing active self-directed learning. In R. Simons, J. van der Linden, \& T. Duffy (Eds.), New learning (pp. 83-101). Dordrecht: Kluwer.

Van Luit, J. E. H., \& Naglieri, J. A. (1999). Effectiveness of the MASTER program for teaching special children multiplication and division. Journal of Learning Disabilities, 32, 98-107.

Veenman, M. V. J. (1998). Kennis en vaardigheden: Soorten kennis en vaardigheden die relevant zijn voor reken-wiskunde taken [Knowledge and skills relevant to math tasks]. In A. Andeweg, J. E. H. van Luit, M. V. J. Veenman, \& P. C. M. Vendel (Red.), Hulp bij leerproblemen: Rekenen-wiskunde (pp. G0050.1-13). Alphen a/d Rijn: Samson H. D. Tjeenk Willink.

Veenman, M. V. J. (2005). The assessment of metacognitive skills: What can be learned from multi-method designs? In C. Artelt \&
B. Moschner (Eds.), Lernstrategien und Metakognition: Implikationen für Forschung und Praxis (pp. 75-97). Berlin: Waxmann.

Veenman, M. V. J. (2006). The role of intellectual and metacognitive skills in math problem-solving. In A. Desoete \& M. V. J. Veenman (Eds.), Metacognition in mathematics education (pp. 35-50). New York: Nova Science Publishers.

Veenman, M. V. J., \& Beishuizen, J. J. (2004). Intellectual and metacognitive skills of novices while studying texts under conditions of text difficulty and time constraint. Learning and Instruction, 14, 621-640.

Veenman, M. V. J., Elshout, J. J., \& Meijer, J. (1997). The generality vs. domain specificity of metacognitive skills in novice learning across domains. Learning and Instruction, 7, 187-209.

Veenman, M. V. J., Kok, R., \& Blöte, A. W. (2005). The relation between intellectual and metacognitive skills at the onset of metacognitive skill development. Instructional Science, 33, 193211.

Veenman, M. V. J., \& Spaans, M. A. (2005). Relation between intellectual and metacognitive skills: Age and task differences. Learning and Individual Differences, 15, 159-176.

Veenman, M. V. J., Van Hout-Wolters, B. H. A. M., \& Afflerbach, P. (2006). Metacognition and learning: Conceptual and methodological considerations. Metacognition and Learning, 1, 3-14.

Veenman, M. V. J., \& Verheij, J. (2003). Technical students' metacognitive skills: Relating general vs. specific metacognitive skills to study success. Learning and Individual differences, 13, 259-272.

Veenman, M. V. J., Wilhelm, P., \& Beishuizen, J. J. (2004). The relation between intellectual and metacognitive skills from a developmental perspective. Learning and Instruction, 14, 89109.

Vuijk, R. A. J., Reichard, L. A., Rozemond, S., Dijkhuis, J. H., Admiraal, C. J., Aalmoes, H., et al. (2003). Getal en Ruimte [Number and Space]. Houten: EPN.

Wang, M. C., Haertel, G. D., \& Walberg, H. J. (1990). What influences learning? A content analysis of review literature. Journal of Educational Research, 84, 30-43.

Wellman, H. M. (1990). Children's theories of mind. Cambridge, MA: MIT Press.

Whitebread, D., Coltman, P., Pino Pasternak, D., Sangster, C., Grau, V., Bingham, S., et al. (2009). The development of two observational tools for assessing metacognition and self-regulated learning in young children. Metacognition and Learning, 4, 63-85.

Winne, P. H. (1996). A metacognitive view of individual differences in self-regulated learning. Learning and Individual Differences, $8,327-353$.

Zimmerman, B. J., \& Martinez-Pons, M. (1990). Student differences in self-regulated learning: Relating grade, sex, and giftedness to self-efficacy and strategy use. Journal of Educational Psychology, 82, 51-59. 